\title{
PEST Analysis of Digital Fitness Equipment Market Based on Internet of Things Technology
}

\author{
C.M. Yuan \\ Physical Education Institute \\ Weifang Medical University, China
}

\begin{abstract}
By macro environment PEST analysis, digital fitness equipment market based networking technology is the inevitable result of mutual integration between Internet of Things market and fitness market. Digital fitness equipment highlights the interesting and scientific. And it is currently in good political, economic, social and technological environment. Currently, wearable fitness equipment development and promotion is the key. In a word, digital fitness market has great potential for development.
\end{abstract}

Keywords-PEST analysis; digital fitness equipment;Internet of Things

\section{INTRODUCTION}

Internet of Things(IOT) has become one of the key issues of the new round of global economic and technology development at present, the development of Internet of Things has the important practical significance for promoting economic development and social progress. By the end of 2014, the national fitness has risen as a national strategy. Sports industry ushered in golden development in china. The combination of Internet of Things and national fitness is the inevitable result of the knowledge economy era, and also the strategic choice of the top enterprises in the field of digital fitness equipment to gain more profits as well. In the current environment, there is extraordinary significance to use PEST analysis tool to examine the market circumstances of digital fitness equipment based on Internet of things technology. Including political, economic, social and technological analysis, PEST analysis describes a framework of macroenvironmental factors used in the environmental scanning component of strategic management [1] .

\section{POLITICAL ANALYSIS}

\section{A. The National Strategy Layout}

In 2008, IBM chief executive Samuel Palmisano put forward the concept of "smarter planet" for the first time. And then, the world's economic powers regard the Internet of Things as a national strategy to support. The Obama administration has adopted IBM proposed the "smarter planet" strategy. American Recovery and Reinvestment Act of 2009(ARRA) has been singed by Obama, it put forward the research application of IOT technology in education, medical and health fields by increasing government investment. The development of Internet of Things has become the focus of America to promote economic recovery and reshape the competitive state. The European Commission has formulated the "Internet of Things EU action plan" to lead the world the development of the Internet of Things. South Korea introduced a u-IT839, and Japan enacted i-Japan. China's ministry of industry and information technology promulgated "12th FiveYear Plan for Internet of Things” in 2012. It highlights an important task that provides services for communities and families by collecting human physiology and health data [2].

The State Council promulgated "Several opinions on speeding up the development of sports industry and promoting sports consumption” in October 20, 2014. Chinese government actively support the sports goods manufacturing industry innovation and development, by using new technology, new material, new technology, to improve the quality level of the traditional sports activities, and to enhance the technology content of products. The government also encourages the R \& $\mathrm{D}$, manufacturing and marketing on wearable sports equipment, sports equipment, sports fitness guidance technology of functional beverage.[3]

\section{B. Improving and Upgrading the Health Security Policy}

In recent years, chronic disease has become a serious social problem. Traditional medical and health security system, because of focusing on treatment instead of prevention, is enough not to make a large number of potential population getting effective prevention and control. As everyone knows that, the exercise is one of the important means of prevention and control of chronic diseases. How can the use of the Internet, especially the Internet of Things technology to rapidly expand the number of emerging fitness crowd, and make people enjoy the professional fitness guide, successfully fixing these problems becomes a problem of national urgent.

\section{The Promotion of the National Physical Training Standard System}

The National Physical Training Standard System is a basic physical education system in China. However, it is not immutable, and it happens with time. More and more people are aware of the benefits of regular exercise like running, cycling, dancing. And we all live in a huge Internet, so it is very hard to imagine without the support of network. That professional guidance about people how to exercise is not just some experience but is more scientific data. In the fitness field, experience is essential, but now we need to be more scientific, interactive, quantifiable, large amount of information, and timely feedback. And these are Internet of Things can provide.

\section{Monitor and Improve the National Physique Health}

The national physique and health is the foundation of a country can long period of stability. The existing system of national physical fitness monitoring, to a certain extent, basically has realized the national physique data collection and 
reporting. But it has a significant flaw because of the lack of supervision and guidance on the national physique. It needs a strong service background. Because the widespread lack of health literacy and population in China, therefore, the best solution to the national physical fitness monitoring services model is to use network fitness service mode of wide coverage, low cost and strong guidance.

\section{ECONOMICAL ANALYSIS}

\section{A. Hundreds of Billions of Scale of the Internet of Things Industry Market}

At present, the development of the Internet of Things in China is at the initial stage with the world, and technology, industry and application have a certain basis, so showing a good momentum of development. The radio frequency identification (RFID) industry market size has been reached more than tens of billions of dollars yuan, of which the low and high frequency RFID relatively mature. Machine to machine (M2M) terminal number has closed to 1 million. According to incomplete statistics, in 2010 China's Internet market size has closed to two hundred billion yuan. With the smooth implementation of the 12th Five Year Plan of industry, industry of the Internet of Things will be development faster.

\section{B. One Trillion of Scale of the Health Industry Market}

Health economics is a branch of economics concerned with issues related to efficiency, effectiveness, value and behavior in the production and consumption of health and health care.[4] Health industry is a new industry with huge potential market, including medical products, health care products, nutritional food, medical equipment, health care equipment, leisure fitness, health management, health consultation more closely related with human health production and service areas. According to statistics, at present, the stock market value of about health related industries accounted for the total market value of about 13\%. Especially in the developed countries, health industry has become a strong power to drive the whole national economic growth. USA health industry including medical services, medicine production and health management added value proportion accounted for more than $15 \%$ increase in GDP.Canada, Japan and other countries health industry value proportion accounted for GDP more than $10 \%$. Health industry currently accounts for only about 5\%in China , according to the 12th Five Year Planning, to 2015 Chinese health industry output value will reach one trillion, annual growth rate of $20 \%$, a huge potential for development.[5]

The digital fitness equipment market is a very important part in the health industry, and more and more important. With the communion and development of IOT industry and health industry, the digital fitness equipment market will contribute more and more value.

\section{Five Trillion of the Sports Industry Anticipation}

The development of sports industry is the inevitable requirement to improve the physical quality and health level of the Chinese nation, and also is conducive to meet people's diverse sports demand, ensure and improve people's livelihood, conducive to expanding domestic demand, increase employment, foster new economic point of growth, conducive to carrying forward the national spirit, enhance the national cohesion and cultural competitiveness. In the background of the rapid development of the national economy and society and sports, the sports industry of our country has been showing a rapid development momentum. According to statistics, the sports industry in China reached about three million in 2008, the added value of about one hundred and fifty billion yuan, a growth of $16 \%$ in 2007, significantly faster than GDP growth rate.

The State Council promulgated "Several opinions on speeding up the development of sports industry and promoting sports consumption” in 2014. By 2025, a rational layout, perfect functions, a complete system of sports industry willed be basically established. And then, sports products and services will should be more abundant, constantly improvement of the market mechanism, consumer demand increasingly strong, the other industry to drive the effect significantly. And the total scale of sports industry will achieve more than five trillion yuan, which will become an important force to promote the sustainable development of economic society.

\section{Digital Health and Fitness Market}

Digital fitness, also known as the VR network fitness, using the virtual reality(VR) technology, gives a person the feeling of be personally on the scene.

In the second session of the Beijing City Sports Industry Exhibition, the digital fitness equipment based on Internet of Things technology has been successfully launched and attracted many people's eyes, so a large number of orders and successful propaganda also let network fitness equipment R \& $\mathrm{D}$ business to become one of the big winners exhibition.

One of the most popular discussion topics is wearable computing, opened in January 7th 2014 America Consumer Electronics Show (CES), many of the relevant science and technology innovation emerged in multitude. But Gartner Angela McIntyre research director said, although the wearable camera and watch has been got a lot of attention, but digital health and fitness must be one of the most popular areas of the exhibition.

Fitness lovers using wearable electronic products are the most for the vast number of consumer groups. And more consumers interested in the device, namely the more extended its market acceptance. Estimated in 2013, global fitness and individual health care can be created by wearable electronic products, App, service revenue to one billion six hundred million dollars, and to 2016 will grow sharply to five billion dollars.[6]

\section{SOCIAL ANALYSIS}

\section{A. Modern Lifestyle}

More and more people are realizing that there is a connection between heart disease and the lifestyle. Today many people are changing their dietary habits and eating food with less fat and cholesterol. Many are paying more attention to reducing stress in their lives. The number of smokers in the lots of countries is now far below the level of twenty years ago as many people succeed in breaking the habit and as fewer 
people take it up. More and more people are aware of the benefits of regular exercise like running, cycling, or dancing; some have begun to run or ride bicycles to work instead of driving. Millions have become members of health clubs and have made health clubs one of the fastest growing businesses in China today. And now the beneficial effects of these changing attitudes and behaviors are beginning to appear: an encouraging decrease in deaths from heart disease.

\section{B. Network Era and Modern Life}

Since the nineties of the 20th century, the rapid development of network technology, has been a profound impact on people's learning style and working way, communication mode and way of life. According to the latest research report by McKinsey research institutions under the McKinsey Global Institute released today in Shanghai, in 2004, the number of Internet users in China has reached 6.32 billions. [7] Another study showed that, by the end of 2013, the scale of China's mobile Internet users has exceeded 5 billions, more than $1 / 3$ of the total population. [8] More and more we increasingly depends on Network. Taking the bus, people need to network. Even the toilet, people no longer holding a book, but choose to use mobile phone. Of course, when fitness, people also hope to enjoy the convenience experience and enjoy brought by Internet.

\section{Happy and Scientific Fitness Trend}

Now, people not only need to fitness, but also need scientific and happy fitness. More and more physical exercise has been in favor of digital fitness equipment. Digital fitness equipment can not only provide a vivid scene for exercisers, but also can provide observation and feedback of practitioners' physiological data. With the electronic body-building equipment help, fitness is no longer boring, but interest and science are greatly improved.

Wearable devices is now darling. It will embolden the currents of quantifiable life. Wearable devices also let people follow the sign of life and personal activities, and to make one day experience recorded image. Wearing and using such equipment to record the fitness and health has much attraction to young people, so also is the use of the App and the service. It has a significant game characteristics to provide fitness participators to contest with themselves or others, and produces encouraging effect to the wearer. It also can provides the colleagues of the friends of its online community as the goal of close friends. Wearable electronic products for consumers has been brought new impetus to improve the body or health condition.

\section{TECHNOLOGICAL ANALYSIS}

\section{A. The Technology of the Internet of Things}

The core and foundation of the Internet of Things technology is still the Internet technology. It is is the extension and expansion of the Internet technology. It achieves the extension and expansion of the client to any between goods and goods, and it can exchange information and communication. Therefore, the definition of the Internet of Things technology: the radio frequency identification (RFID), infrared sensors, global position system, laser scanners and other information sensing device, as agreed in the agreement, will connected anything to the Internet, is to achieve the exchange of information and communication, and to achieve a network technology of intelligent identification, location, tracking, monitoring and the management.

At present, the Internet of things technology development has been relatively mature. The Internet of Things technology has been applied in medical, public transportation, production safety, food security, intelligent Home Furnishing etc.,.

\section{B. The Technology of the Digital Fitness Equipment Based on Internet of Things Technology}

The core and foundation of the technology of the digital fitness equipment based on Internet of Things technology is still the Internet technology. To some extent, we can say, the digital fitness equipment technology is more of the application of network technology to fitness equipment. Because of the huge market potential, many companies in the world have investment in the development of digital fitness equipment.

1) Distinguish from direction: At present, there are mainly two development way of digital fitness equipment technology. The difference between them is mainly transverse and longitudinal development. The former emphasizes the application of Internet of Things technology, focusing on the development of technology. However, the latter is more emphasis on fitness equipment with the help of Internet of Things technology to extend the function of itself.

In the transverse development, Nike+ Training Club(N+TC) is very popular. Through these applications, Nike can digitally generated female athletes with global connections, and guide and inspire them.[9]

In the longitudinal development, LivePod is very representative. It based on three axis accelerator and personalized energy consumption model. And it can collect the fitness movement, including the type of motion state of fitness, movement, rhythm, time every minute motion energy consumption values, the movement of fat and carbohydrate metabolism ratio and the amount and form of motion capture and other fitness index. It realizes the real-time perception of fitness of human behavior in daily life.

2) Distinguish from function: Functional difference is mainly reflected in fun or scientific. Because sports and games have a natural link, so technically difficult to completely separate area for added fun or scientific. Interesting mainly reflects in acceptability, and to make fitness happier. However, science is mainly reflected in the quantity and quality of exercise, so that fitness has become a scientific and rational. The former through simulation scenarios, makes practitioners on the ground, can get more pleasure and improve ethical values of fitness. The latter, by means of a substance linked network, real-time acquisition, transmission of data and provide guidance, can improve the value of fitness tools.

\section{SUMMARY}

Digital fitness equipment market has a good political, economic, social and technological environment, and has great potential for development. Sports related enterprises should seize the historical opportunity for development and actively carry out research and production of fitness equipment of 
digital products, to boost the development of sports industry and to promote national fitness faster and better development.

\section{REFERENCES}

[1] PEST analysis, http://en.wikipedia.org/wiki/PEST_analysis

[2] http://www.gov.cn/zwgk/2012-02/14/content_2065999.htm

[3] http://www.gov.cn/zhengce/content/2014-10/20/content_9152.htm

[4] http://en.wikipedia.org/wiki/Health_economics

[5] http://www.962518.com/topics/2012-04-07/3029219.html

[6] http://www.esmchina.com/ART_8800128991_1300_2200_4300_35fafa 28.HTM

[7] http://sh.people.com.cn/n/2014/0725/c176737-21772166.html

[8] http://www.financialnews.com.cn/wh_138/ly/201403/t20140328_52692. $\mathrm{html}$

[9] http://sports.sina.com.cn/crazysneaker/2014-10-23/17137380982.shtml 